\title{
Upward shifts in elevation - a winning strategy for mountain viticulture in the context of climate change?
}

\author{
Lukas Egarter Vigl ${ }^{1, a}$, Arno Schmid ${ }^{2}$, Franz Moser ${ }^{3}$, Andrea Balotti ${ }^{1}$, Erwin Gartner ${ }^{4}$, Hermann Katz ${ }^{3}$, Siegfried \\ Quendler $^{4}$, Stefania Ventura ${ }^{2}$ and Barbara Raifer ${ }^{2}$ \\ ${ }^{1}$ Eurac Research, Viale Druso 1, I-39100 Bolzano, Italy \\ ${ }^{2}$ Laimburg Research Center, Laimburg 6, I-39040 Ora, Italy \\ ${ }^{3}$ Joanneum Research, Leonhardstraße 59, A-8010 Graz, Austria \\ ${ }^{4}$ Obst u. Weinbauzentrum Kärnten, Schulstraße 9, A-9433 St. Andrä, Austria
}

\begin{abstract}
The advent of global climate change has major impacts upon viticultural production. Changes in the spatial limits of wine production are already being observed around the globe; vineyards are now viable at higher elevations and more polar latitudes. Climatic conditions are also threatening production in existing appellations. Therefore, sound management strategies are vital to maintain high-quality wines and varietal typicity, and to respond to changing market conditions. In mountainous regions such as the European Alps, new production areas at higher elevations are increasingly considered to be a promising solution. However, the suitability of viticulture in general, and even specific varieties of wine grapes, can change drastically across short distances in complex mountain terrain. Variations in temperature and radiation accumulation directly influence plant suitability, yield quantity, and quality. This paper shares initial findings from the REBECKA Project, a transnational research initiative designed to assess the impacts of climate change on mountain viticulture and wine quality in South Tyrol (Italy) and Carinthia (Austria). A three-part approach is utilized to better assess these dynamics: (1) historical crop yield data from local vineyards are assessed, (2) plant phenology stages and polyphenolic compounds of the Pinot Noir variety are analyzed along an elevation gradient and related to bioclimatic indices, and (3) a suitability map is developed that considers small-scale topographic and agro-environmental conditions. Taken together, these components contribute in clarifying many of the opportunities and threats facing high altitude viticulture in a changing world and provide new insights for sound decision-making in alpine vineyards.
\end{abstract}

\section{Introduction}

Global climate change is proceeding at an unprecedented rate. According to the Intergovernmental Panel on Climate Change (IPCC), the past century has seen the global average temperature rise by more then $1{ }^{\circ} \mathrm{C}$ and all climatic models agree that drastic temperature increases will continue to occur through 2100 [1]. These temperature changes are likely to affect agro-economic activities, including grape growing, both temporally and spatially [2]. In fact, over the past years the land area devoted to viticulture at the cooler end of the suitability spectrum has increased globally [3], reflecting the trend towards a warmer climate. While most research on the subject focuses on the latitudinal shifts towards the poles (i.e. in southern UK, Scandinavia, northern Germany) and its consequences for wine production, only little attention has been given so far to the emerging wine producing areas in mountainous terrain.

Recent vineyard plantings in the Alpine wine growing region of Alto Adige, however, are more frequently located at higher altitudes than in the past (Fig. 1), confronting traditional viticulture practices with a number of new challenges: harsher environmental conditions, shortened growing seasons, reduced yields and poorer soil structures. Understanding and assessing the opportunities and risks 
grape growers are likely to face in these regions is thus crucial for sustainable, quality-oriented viticulture [4].

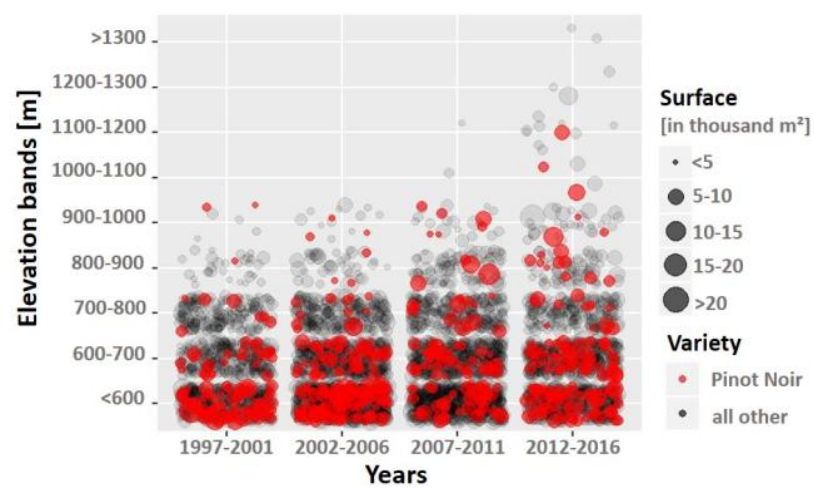

Figure 1. Altitudinal distribution and size of new vineyard plantings in the Alto Adige wine growing region (IT) since 1997. Pinot Noir variety superimposed in red.

In this work, we present some preliminary results of the transnational EU-funded "REBECKA" project (Interreg VA IT-AT: ITAT1002, duration: 2017-2019) that has been specifically designed to address the impacts of climate change on the mountain wine growing regions of Alto Adige (Italy) and Carinthia (Austria). The project is composed of three main parts. First, historic yield data from different wineries are analyzed. Herein, the main focus is given to the assessment of spatiotemporal shifts in the dates of harvest, and in the yield quantity and quality (mainly sugar and acidic content). Second, plant phenology stages (bud burst, flowering, ripening, harvest) and polyphenolic compounds are analyzed across different elevation ranges, covering warm, intermediate, cold and extreme sites. Finally, a spatially explicit land suitability map is developed, based on bioclimatic indices that characterize the wine growing potential of the study sites. The work presented in this paper, however, is limited to the Alto Adige study site (Fig.2).

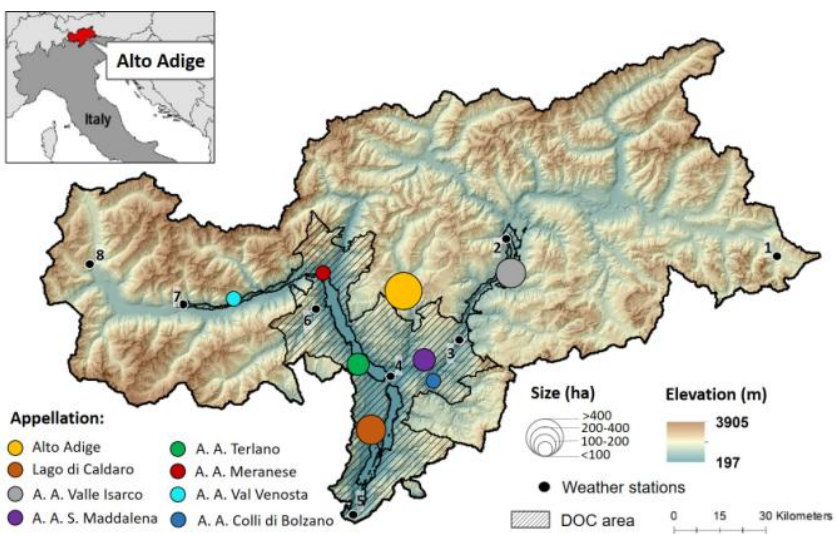

Figure 2. Distribution and size of the eight wine appellations in Alto Adige. Black dots represent locations of selected weather stations.

\section{Material and Methods}

\subsection{Study area}

The Alto Adige wine region is located in the Central Alps and covers an area of approximately 5400 ha (Fig. 2). It is situated between an Alpine climatic zone and a Mediterranean one, with vineyards usually growing between $200 \mathrm{~m}$ and $1100 \mathrm{~m}$ above sea level (a.s.l.). Some extreme sites reach $1300 \mathrm{~m}$ a.s.l. The current viticultural area includes both red and white cultivars $(40 \%$ and $60 \%$, respectively). The main varieties are Pinot Grigio, Pinot Blanc, Chardonnay and Pinot Noir, along with a few local varieties such as Schiava (Vernatsch), Lagrein and Gewürztraminer. Currently, the South Tyrolean wine growing region is divided into eight appellations (federally designated regions, called "controlled designations of origin - DOC"): Kalterersee, Eisacktaler, St. Magdalener, Terlaner, Meraner, Vinschgau, Bozner Leiten and Südtiroler.

\subsection{Yield data from wineries}

Historic yield records from five important local wineries (Tramin, Nals, Eppan, Kurtatsch, and Eisacktal) across Alto Adige have been collected and statistically analyzed for quantitative and qualitative parameters at the land parcel level. The main analyses included the assessment of spatiotemporal changes in yield quantity, sugar and acidic content and harvest dates in relation to topo-climatic site conditions. In total, the past 20 years of wine production have been analyzed, covering approximately 1000 ha of land ( $20 \%$ of total Alto Adige wine growing surface).

\subsection{Phenological data and grape maturity records}

At thirty different vineyard plots, the phenological stages (bud burst, flowering, ripening and harvest) were assessed over the vegetation period (April 1st to October 31st). These sites have been selected in order to cover all eight wine appellations and most of the variety in topo-climatic characteristics (i.e. different altitudinal and topographical patterns) of the study area. Pinot Noir was selected as the reference variety for the field surveys as it is cultivated over the entire altitudinal gradient, including vineyards located between $250 \mathrm{~m}$ and $1100 \mathrm{~m}$ a.s.1. Moreover, at each site, maturity tests were performed that analyzed the polyphenolic compounds (i.e. pH-value, sugar and acidic content) of the grapes at specific points in time. Finally, both plant-growth data and polyphenolic compounds were related to bioclimatic indices, in order to estimate their reliability for predicting plant growth and grape quality compounds.

\subsection{Climate data and zoning approach}


A 20-year time series of daily climatological observations from a network of 80 different stations has been used to calculate bioclimatic indices. These indices are commonly used to characterize wine-growing regions worldwide in a standardized way and as a suitability-zoning tool, as there is a significant relationship between plant growth and heat accumulation [5]. A multiple linear regression model has been applied to spatialize the climatological data into a high-resolution grid, using topographic parameters such as elevation, slope, aspect and potential solar radiation as predicting variables. Finally, climate maturity groupings were built based on growing degree days [6] to characterize wine-growing suitability at a parcel scale.

\section{Results and discussion}

The Alto Adige wine-growing region presents great diversity, both in terms of topo-climatic conditions and cultivated varieties. The cultivars include both white and red varieties and are spread across an altitudinal gradient of approximately $1000 \mathrm{~m}$. This results in large differences between single production zones, including cool, intermediate and warm regions [7]. Moreover, over the past 50 years, the South Tyrol wine region has registered a temperature increase of more than $1^{\circ} \mathrm{C}$, directly affecting

Table 1. Climate records of selected weather stations in Alto Adige: locations, elevation, time periods, trend over the period of record (POR) and current growing season average temperature (GST, for April-October).

$\begin{array}{lllll}\text { Location } & \begin{array}{l}\text { Elevation } \\ {[\mathrm{m} \text { a.s.1. }]}\end{array} & \text { Time Period } & \begin{array}{l}\text { Trend } \\ {\left[{ }^{\circ} \mathrm{C}, \text { POR }\right]}\end{array} & \begin{array}{l}\text { Current } \\ \text { GST }\left[{ }^{\circ} \mathrm{C}\right]\end{array} \\ \text { Sesto } & 1310 & 1956-2016 & 1.0 & 12.4 \\ \text { Varna } & 590 & 1956-2016 & 1.2 & 17.4 \\ \text { Barbiano } & 490 & 1977-2016 & 0.8 & 17.5 \\ \text { Bolzano } & 254 & 1984-2016 & 1.5 & 19.4 \\ \text { Salorno } & 212 & 1977-2016 & 1.5 & 19.6 \\ \text { Pavicolo } & 1200 & 1972-2016 & 1.4 & 12.8 \\ \text { Silandro } & 698 & 1956-2016 & 1.0 & 16.6 \\ \text { Monte } & 1310 & 1967-2016 & 0.9 & 13.4 \\ \text { Maria } & & 48 \text { years } & 1.2 & 16.1 \\ \text { Average } & & & \end{array}$

crop growth by advancing phenological stages and by lengthening the overall growing season (Tab. 1).

For some crops, like wine grapes, a warmer climate can have a positive impact by extending their climatic niche into areas formerly considered to be too cold. As an increase in surface temperature often directly triggers an advancement of plant phenology, earlier dates of fruit pick would be expected. The historic yield records from five different wineries, however, depict that harvest dates have not considerably advanced during the overall period of study (1995-2016). In the first decade of the time series, an advancement in harvest dates is visible that coincides with increased grape maturity levels (sugar content). This trend, however, is counterbalanced by the second decade of records, where fruits are picked later and sugar levels flatten out (Fig. 3). Producers most likely take advantage of warmer climate conditions to harvest fruits at a greater level of ripeness. Thus, changes in plant phenology stages due to warmer climatic conditions do not necessarily entail a change in harvest dates.

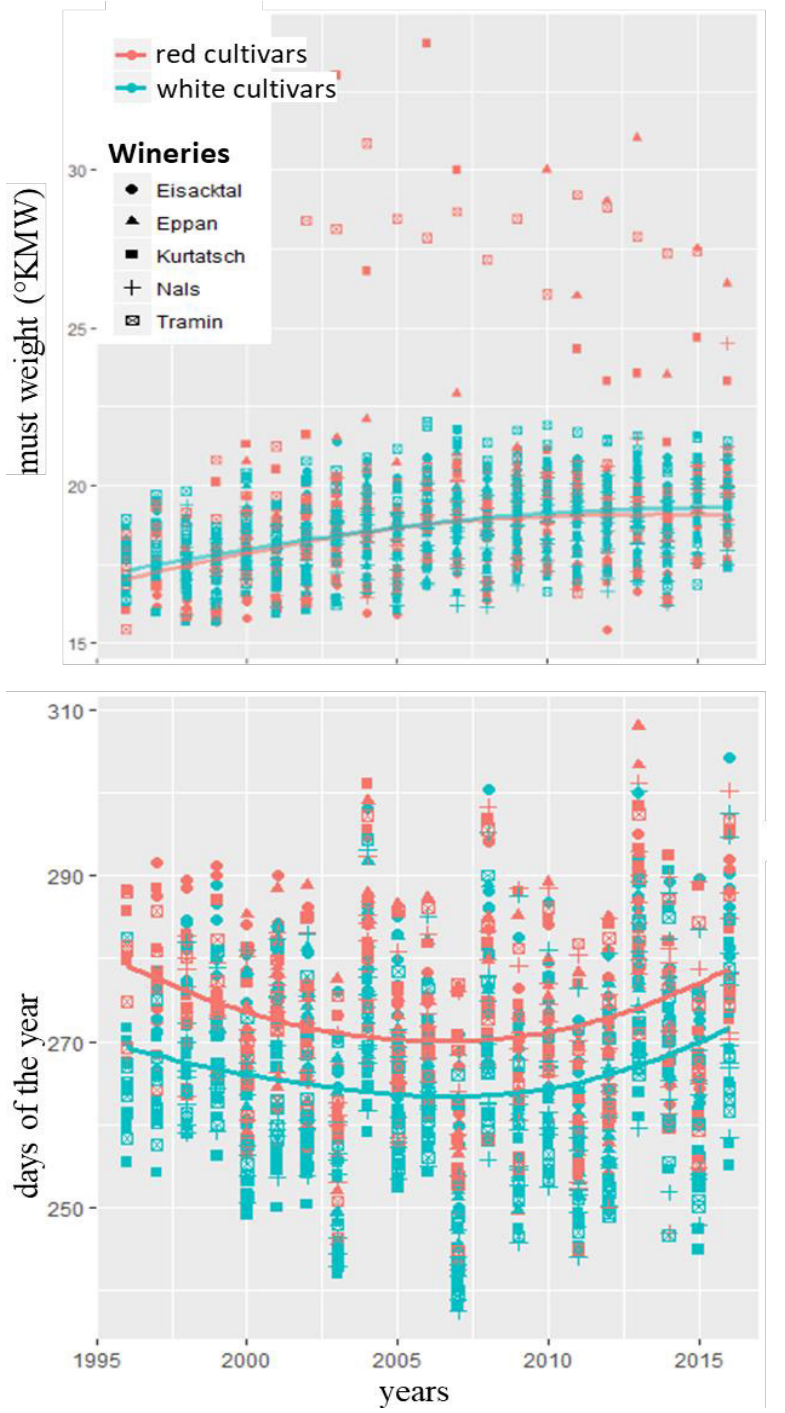

Figure 3. Long-term development of sugar content (above) and harvesting dates (below). Colors represent red and white cultivars, while the symbols depict the five different wineries under study.

The preliminary analysis of phenological data at the 30 different vineyard plots confirmed a strong relationship between the vegetation cycle and climate properties, especially in the beginning and in the end of the growing season. In fact, budburst events of 2017 could be directly related to altitude, which is used as a proxy for the different climatic site conditions in this study (Fig. 4). This strong dependency, however, decreases once budburst occurs and the growing season progresses. Favored temperature regimes after budburst most likely allowed Pinot Noir 
grapes to develop similarly along the entire altitudinal gradient, as only minor variations in the length of flowering and ripening stages across plots could be observed. Towards the end of the growing season, elevation is decisive in regulating grape maturity levels and the correlation coefficients between plant growth and elevation become significant once again. Thus, our first field observations suggest that vineyards at the cooler limits of suitability experience an increased exposure to climate extremes (i.e. spring or autumn frosts) because decisive phenological stages for quality wine production (i.e. harvesting) are directly related to climatic site conditions during the early- and late-stages of the growing season, exactly when these extremes are most likely to occur,

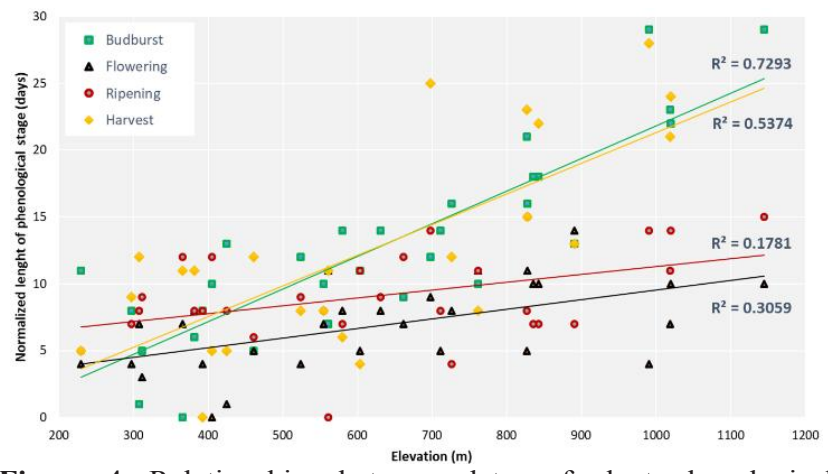

Figure 4. Relationships between dates of plant phenological stages and elevation. Dates are normalized to the first vineyard plot entering the respective phenological stage. Elevation is used as a proxy for climate site condition.

Moreover, for each vineyard block, grape compounds were compared to different bioclimatic indices to estimate index performance in predicting chemical properties (Fig.
5). Specifically, the Winkler index, Huglin Index, Gladstone index, Cool Night Index and Growing Season Average Temperature were compared with grape compounds such as sugar content, $\mathrm{pH}$-value, potassium concentration, and malic, tartaric and total acid. Overall, no single index could be identified that explains all variables in a statistically significant manner. However, except for the sugar levels, heat-summation-based indices performed best in predicating chemical grape compounds. Of these, the Winkler index most consistently fits the data. Thus, it has been selected as the most representative index for use in climate suitability mapping.

The mountainous Alto Adige region contains many vineyards near the cooler limits of wine grape cultivation. On the Winkler index (WI), these areas mostly range between classes I and II (Fig. 6), making this region especially suited to white and early ripening varieties (i.e. Pinot Noir). However, the warmest locations in the region, such as the lowlands around Bolzano, receive temperature sums in excess of $1700{ }^{\circ} \mathrm{C}$, qualifying them as region III areas and for the production of high-quality red cultivars. These different classes occur in relatively close proximity due to the huge altitudinal gradients in the region. The coldest climate zones (WI Ia) in Alto Adige theoretically reach up to $1300 \mathrm{~m}$. However, the current limit for quality wine production actually lies at approximately $1100 \mathrm{~m}$, due to other environmental factors such as more frequent weather extremes [8]. In such extreme conditions, mostly hybrid varietals such as Solaris are cultivated. The cool climate region WI $\mathrm{Ib}$ is characterized by elevations up to $1100 \mathrm{~m}$ and early ripening cultivars such as Müller Thurgau, as well as Chardonnay and Pinot Noir for sparkling wine production. 


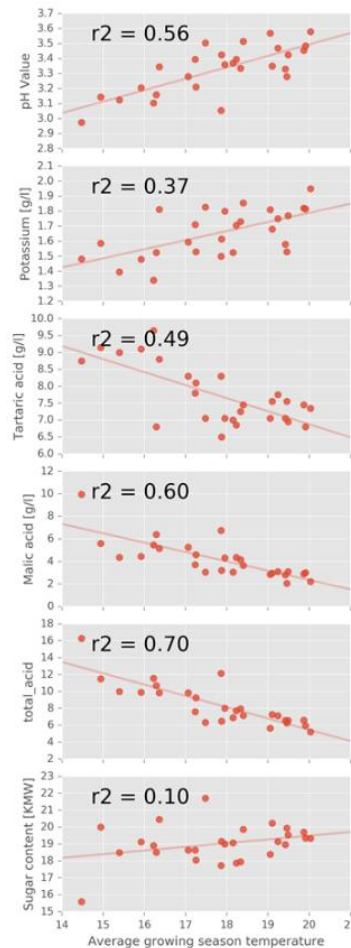

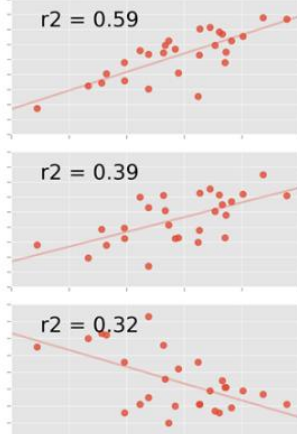

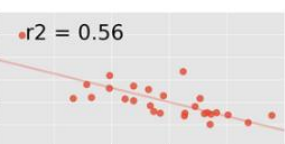

${ }^{\circ} \mathrm{r} 2=0.64$

$\therefore 8 \div$

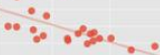

$r 2=0.17$

$\therefore \because \because \because$.

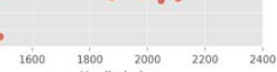

$\begin{array}{lllll}1600 & 1800 & 2000 & 2200 \quad 2400\end{array}$
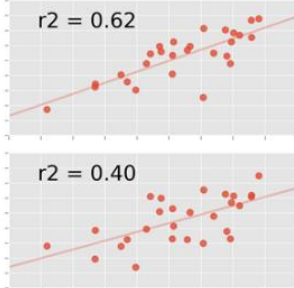

$r 2=0.40^{\circ}$
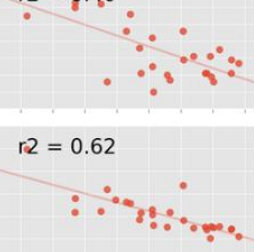

$r 2=0.71$

$\therefore-\therefore \therefore$

$r 2=0.20$

$\because \because 8 \% \div \div$

is

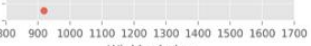

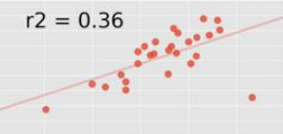

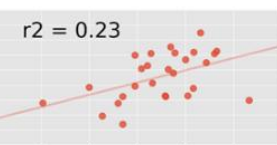

$r 2=0,26^{\circ}$

$\therefore \because 00^{\circ}$

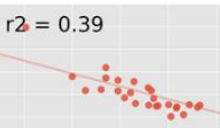

$r 2=0.44$

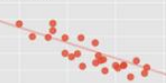

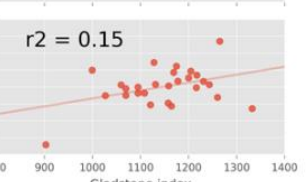

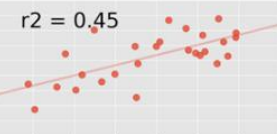

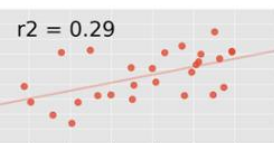

$r 2=0.52$
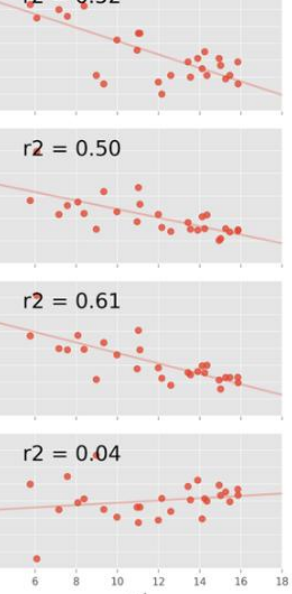

Figure 5. Relationships between different bioclimatic indices and wine grape compounds of Pinot Noir cultivar for the year 2017. Regression lines and correlation coefficient superimposed.

Winkler index region II areas are suited for varieties like Pinot Gris, Pinot Noir, Gewürztraminer and Chardonnay.The final Winkler region found in South Tyrol is classified as region III and extends upward to approximately $450 \mathrm{~m}$ in the sunniest and warmest areas. These sites are characterized by varieties like Schiava, Lagrein, Merlot and Sauvignon Blanc.

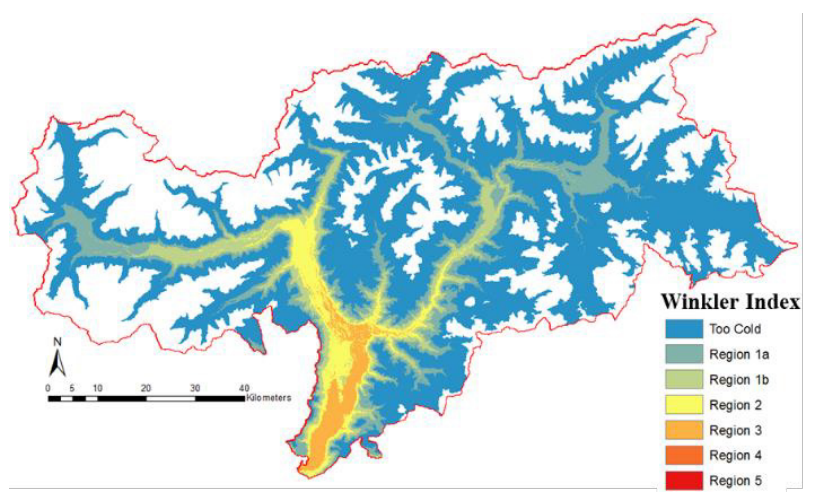

Figure 6. Heat accumulation groupings using the Winkler bioclimatic index based on an averaged temperature map of the period 1991-2010.

\section{Conclusion}

As increasing temperatures associated with global climate change continue to be felt across the landscape, opportunities for wine grape cultivation are expanding into areas that were previously unsuitable. In particular, areas at extreme latitudes and elevations (i.e. mountainous regions) are experiencing increases in wine grape production. There is therefore a need to analyze changing viticulture suitability for growers and decision makers. Increasing temperatures alone, however, cannot be directly linked to enhanced suitability of mountain viticulture. Such trends suggest enhanced potentials of cool climate viticulture, but also critically mask the additional impact of the more highly variable climate regimes predicted by climate models. In fact, the inter-annual variability and extreme weather events that already threaten productivity in mountain areas are likely to become more frequent and intense. Thus, those who choose to cultivate these newly suitable areas face an increased risk of reduced overall production and catastrophic weather events. While warmer climates might open new opportunities for some varieties, for others, especially existing autochthonous cultivars, higher temperatures come along with insuperable challenges for physiological plant growth. Farmers must therefore be aware of these changing environmental conditions in order to meet market demands and consumer expectations for specific products. Moreover, the economic investments associated with opening new vineyard land must be carefully considered in this context. This is especially difficult in newly suitable viticulture areas, where farmers may lack expertise and information about wine cultivation, and take unnecessary monetary risks. As climate change alters mountainous regions, understanding the risks and opportunities it presents is vital to maintaining a socio-ecologically sustainable viticulture system.

\section{References}


1. IPCC. Fifth Assessment Report of the Intergovernmental Panel on Climate Change. Synthesis Report - Summary for Policymakers. Geneva, Switzerland, $151 \mathrm{pp}$, (2014).

2. A. Nesbitt, B. Kemp, C. Steele, A. Lovett, S. Dorling. Impact of recent climate change and weather variability on the viability of UK viticulture combining weather and climate records with producers' perspectives. Aust J Grape Wine Res 22, 324-335 (2016).

3. G.V. Jones. Climate, grapes, and wine: structure and suitability in a changing climate. Acta Hort 931,19-28 (2012).

4. L. Egarter Vigl, E. Tasser. Die Weinbau-Zonierung in Südtirol. SZOW 8, 6-9 (2017).

5. J. Tonietto, A. Carbonneau. A multicriteria climatic classification system for grape-growing regions worldwide. Agric For Meteorol 124, 81-97 (2004).
6. M. Amerine, A.J. Winkler. Composition and quality of musts and wines of California grapes. Hilgardia 15: 493-675 (1944).

7. L. Egarter Vigl, E. Tasser, S. Williams, U. Tappeiner Defining suitable zones for viticulture on the basis of landform and environmental characteristics: a case study from the South Tyrolean Alps. Fifth International Congress on Mountain and Steep Slope Viticulture, Congegliano. Italy (2017).

8. R. Zorer, D. Rocchini, M. Metz, L. Delucchi, F. Zottele, F. Meggio, M Neteler. Daily MODIS land surface temperature data for the analysis of the heat requirements of grapevine varieties. IEEE Transactions on Geos (2013). 